Int. J. Electrochem. Sci., 15 (2020) $10844-10853$

\title{
Temperature Effect on Corrosion Behavior of 304LN Stainless Steel and Carbon Steel Rebars in Chloride Contaminated Concrete Pore Solution Using Electrochemical Method
}

\author{
Bo Dong ${ }^{1}$, Xiao-Dong Wen $^{2, *}$, Lei Feng ${ }^{2}$ \\ ${ }^{1}$ Lancang-Mekong International Vocational Institute \& School of Vocational and Technical Education, \\ Yunnan University of Nationalities, Kunming 650504, Yunnan, China \\ ${ }^{2}$ Zhejiang Engineering Technology Research Center of Civil Engineering Industrialized Construction, \\ Ningbo University of Technology, Ningbo 315211, Zhejiang, China \\ *E-mail: wenxiaodong@ nbut.edu.cn
}

doi: $10.20964 / 2020.11 .59$

Received: 2 May 2020 / Accepted: 13 June 2020 / Published: 30 September 2020

Corrosion of steel rebars in alkaline environments can be exacerbated in hot weather conditions, which has a direct impact on the durability of reinforced concrete structures. Here, the corrosion resistance of $304 \mathrm{LN}$ stainless steel and carbon steel rebars were studied using the electrochemical impedance spectroscopy and potentiodynamic polarization techniques in chloride contaminated concrete pore solution at various temperatures. Corrosion rate of all samples had increased with increasing exposure temperatures from $25^{\circ} \mathrm{C}$ to $55^{\circ} \mathrm{C}$. Polarization data revealed enhanced corrosion resistance of stainless steel rebar under hot alkaline environments compared to carbon steel rebar which can be attributed to the formation of chemically stable, thin and passive oxide layer caused by chromium into the stainless steel structures. The electrochemical results indicate that $304 \mathrm{LN}$ stainless steels reveal a higher impedance with a higher durability, lower corrosion current density, and higher corrosion resistance than carbon steel.

Keywords: Corrosion resistance; Concrete pore solution; Stainless steel rebar; Temperature effect; Electrochemical techniques

\section{FULL TEXT}

(C) 2020 The Authors. Published by ESG (www.electrochemsci.org). This article is an open access article distributed under the terms and conditions of the Creative Commons Attribution license (http://creativecommons.org/licenses/by/4.0/). 